\title{
BESPRECHUNGSAUFSATZ
}

\section{Ecology and Economy - Socio-Economic Development in the Third World and the Problems of the Conservation of Natural Resources}

Since the middle of the 70 s more and more scientists faced environmental problems. But because of the complexity of the often varying problems and the perspective of the disciplines these scientists represent, there have been few attempts at a more systematic view. The energy crisis, in particular, especially led to the attention paid to these problems, and the modes of agricultural production - forced by an increasing population came into the scope of scientific research. As well as these, we must take into account the overwhelming migration problems which lead, in terms, to an unacceptable form of urbanization. So a new way of viewing economic development in the Third World came about: ecodevelopment.

Thisway, the intercessors hope to arrive at a form of development, which satisfies the needs of the population, even of a fast growing one and by doing so, to avoid the conglomerative industrial-urban centres surrounding the important harbors and the capitals in the developing countries. An intensive criticism of modernism and progress is often involved here. They do not take into account that the development in these countries, the satisfaction of the needs and the conservation of natural resources, such as air, water and soil, within the existing situation are not to be realized without sophisticated know-how, methods and technologies - all of which are usually possessed by industrialized countries. On the other hand, the developing countries do need a way of development that is ecologically acceptable, and not expensive in the conservation of natural resources; they cannot afford capital intensive concepts, and even if they could, they would not pay for them as their priority lies in industrialization.

The elements which would add up to a solution are, therefore, obvious, but it seems that the more that is known about the problem the more complicated becomes. There is an enormous technological gap between the Third World and the industrialized countries as the former lack the scientific potential to develop the technologies which they need. It is also a question of the systematic international division of labour. The following monograph either discuss the general problems of the relationship between economy and ecology or they report the special situations of individual countries; the experiences of China are particularly interesting. In these contributions many of the problems just introduced are faced. 


\section{Development and the Conservation of Natural Resources}

R. Riddell presents a monograph concerning the concept of ecodevelopment, which is perceived as an alternative to the capitalist and socialist ways of development in the Third World. Ecodevelopment would use the existing resources for greater human progress than do capitalism and communism, it would lead to a socially, economically and environmentally balanced future (p. 14; p.xiii). This concept he views as necessary because the form of development of the Northern industrialized countries, with its pollution is viewed as not acceptable (p.xii), therefore the low income countries need an alternative way of development. What one expects from this book is a concept for socio-economic development that shows the way to a future which is characterized by a relative harmony between the coming changes and the natural environment. Expectation, however, of the construction of an alternative to the existing development in the Third World are not met.

In its presentation of modernity, self-sufficiency and appropriateness as the ideals of ecodevelopment (p. 161), and adequate food, clothing and shelter as its aims (p. 128), this concept is not particularly original. So, unfortunately Riddell does not reach very far when he sums up the principles of ecodevelopment (pp. 9-13). To generate political will to break with Northern ways of development, to reach to more favourable trade adjustments for the low income nations, to reduce hunger by an increasing to use of alternative food reserves, greater self-reliance in health services and supply of food and construction materials, as well as the need for rural reforms greater employment, education and medical services, the protection of environment, conservation of resources and the balance of the resources with the population, to guarantee survival, none of these principles are new and specifically placed in his concept of ecodevelopment. As a systematic combination of these elements is lacking here, his treatment does not go any farther than existing discussions about the environmental problems of the Third World, concepts of basic needs and self-reliance.

The problem that is basic to Riddell's book, is that he does not start with the ongoing problems of environment and development in the Third World, with industrialization, soil erosion, growth of population, migration and their influence on nature. He does not discuss these interwoven problems and the - in fact - existing problems of modes of development already in use, but as it is obvious to him that "underdevelopment is linked structurally to overdevelopment" (p. 79), he immediately asks: "What is the form and content of a development model which is economically equitable, socially ennobling and environmentally balanced?" (p. x.). It is much more difficult this way to arrive at the policies which the Third World needs, as Riddell himself put them (pp. 113-114): grass roots endeavour, local and regional development and greater self-reliance. But instead of demanding the attention of politicians he addresses himself to administrative cadres (p. 177) and puts his faith in election of "responsible and truly representative leaders" (p. 178), by whom - as he is sure - ecodevelopment policies cannot be overlooked (ibid.). He completely underestimates the influence of the politicians who are in power, 
while expecting the administrative cadres under their authority to undergo an ideological transformation, and hoping for an ecodevelopmentally influenced new generation of politicians.

Besides a discussion of the model presented in this book there is a presentation of attempts to solve specific problems. While it is quite reasonable to see the growth of population in the context of the utilization of resources (p. 136), it is more important to face the cultural reasons for this development - the need of a rural family for farm labour and the lack of education and employment in urban surroundings. His demand for "transfer of technological concepts between likethinking nations" (ibid.) and for information flows (p. 170) is neutralised by the Third World's insufficient science and research structure which is as a rule not oriented on the national problems. Within this context it is precisely his call for more self-reliance and for a break with the Northern countries that hinders Riddell's concept from utilising the international division of labour for the appropriate satisfaction of technological needs.

The question of what the role of industrialized countries is or should be in the environmental problems of the Third World, is one which is also discussed and analysed, using the example of the third World policies of West Germany, by Volkmar J. Hartje (1982). He asks what is the role of such policies in leading to an ecologically acceptable devolopment in developing countries. Unlike Riddell he looks at these problems not as the results of capitalist or communist development but as the results of industrialization, urbanization and the endangering of soil, water and vegetation which is induced by poverty-especially in the rural regions (p. 7). This more pragmatic approach leads him close to the problems and to the questions what to do and how to do it; instead of calling for an alternative development he faces the actual problems and different situations in urban and rural regions. In this context it is important to see that in Third World countries the environmental problems are often more heavy than they are in industrialized countries as the national industries are often concentrated in the capitals and bigger ports. The rural regions, however, differ fundamentally because of the problems of soil erosion, changes in agricultural ways of production which are necessary because of the growth of population and the loss of agricultural areas (p. 13).

In the evaluating the policies of the industrialized countries assisting the development of the Third World Hartje gives an excellent and well informed overview of the environmental problems and their systematic interweavings; this is not only interesting in his context but also a good introduction to those interested in these problems. Here, he points to the problems of the rural poor to survive, to the need for increasing production of food and the intensification of production methods in the context of a growing rural population.

The other field of environmental problems which he represents is the increasing industrialization; here, Third World countries still often view on the protection of environment as a luxury of the industrialized countries. In this context Hartje argues that the protection of environment does not necessarily bring about a reduction in other investments, but that the way of recycling organic wastes and industrial and household wastes 
can at the same time make important raw materials available (p. 41). Furthermore he points out, that there is no negative connection between regulations to protect the environment and foreign investments. On the one hand, in his view the MNEs do not cause the environmental problems in the Third World but contribute to them, on the other hand the threshold countries are strong enough to force them to implement environmental protection, and the enterprises prepare themselves technical before settingup to adjust in this way, which is cheaper than doing so afterwards (p. 42 and 56). So environmental problems are mainly created by the developing countries themselves, for instance by the use of technically antiquated plants.

As the third environmental problem in the Third World he points to increasing urbanization. Here the big cities are growing enormously and leading to problems which are also typical of the industrializes countries (p. 42). Very different to the industrialized countries are the environmental problems induced by the spreading of slums. Here he pays attention to the missing infrastructure that causes the contamination of rivers and groundwater by wastes and waste waters and carriers of disease (p. 44). The installing of appropriate infrastructures costs more than the developing countries can invest and is prevented by the lack of institutions and of qualified personnel (p. 49/50).

In his book, therefore, Hartje gives a detailled and well informed overview on the rural, urban and industrial environmental problems. The analysis of the capabilities of the Third World countries to solve the problems is missing; most of all the capability of these countries to develop appropriate technologies, to find appropriate ways of urban and rural development and to find suitable ways of agricultural production. These are the main problems that are to be solved if the system of underdevelopment, poverty and the destruction of environment is to be broken. And here it becomes quite clear, that the countries of the Third World need the technical and scientific assistance of the industrialized countries - even if the technologies used in the highly developed countries normally do not fit into the Third World situation.

As the developing countries are not able to break out of the systematic context, Hartje's analysis of West German policies to assist the development in the Third World to become environmentally more acceptable is quite an important work. He wants the industrialized countries to help in the setting-up of environmentally oriented institutions (which depends on the interest of the developing countries and the existing circumstances of control); in the development of technologies to reduce the costs of environmental control and to improve the sanitary situation; in the conservation of natural resources (reforestation and control of soil erosion), putting the emphasis on rural development projects to reduce rural poverty and poverty induced environmental problems, and to reinforce the energy supply in rural regions (p. 59/60). In evaluating the policies in this way, Hartje finds out, that the ecological aspects are only to very small extent integrated into the existing concepts; since 1980 there is a bilateral cooperation for the "Conservation of Natural Resources" that pays attention to the problems of rural development and energy supply (p. 67). 
So there is a difference between the realized projects of German developmental assistance and the programmatic level. Although on the programmatic level the need for the conservation of resources is given due attention, and although rural regions are especially emphasised, Hartje points out that no projects are planned to improve the rural energy situation on a broader basis, for example by fire wood plantations (p. 91). Otherwise, if there are projects necessary to conserve natural resources which lead to higher capital-intensive activities, the developing nations do not start them because of budgetary limitations and the higher priority given to the building-up of the infrastructure and industrialization by national aims of development (p. 95). Therefore, the policy of developmental assistance of the industrialized countries has not only to assist in the conservation of the natural resources and the environment, but also to introduce these conservations.

As the developing countries are not able to manage their problems by themselves, Hartje argues that there is a strong need for the assistance of the industrialized countries; their role should be to adjust their programmes of developmental aid to the needs that exist in the protection of nature and the conservation of resources (p. 105). Here he identifies as main problems the erosion of natural resources for agricultural development, the inadequate sanitary situation and the increasing industrial and urban pressure on environment (ibid.). So far it is important that Hartje has focussed our attention on the conditions necessary to overcome these problems and on the role of industrialized countries within this context; and the developmental assistance has a particularly important role. Furthermore, it is his differing position from Riddell which makes it interesting to read this book; contrary to him Hartje points out that the conservation of environment and resources in the Third World is not to be realized without the industrialized countries, and he points to the need for a change in the programmes of developmental assistance. The importance of the national consciousness of environmental problems and of the national environmental policies in the countries of the Third World on the one hand, and the contribution of the policies of developmental aid in industrialized countries as well as their technological assistance on the other hand, is also pointed out by the work of Weimert/Kress/Karper (1981). On the example of the recycling of wastes and waste waters they demonstrate the systematic context and problems of environmental protection. Here they show, that increasing development and a rapidly growing population lead to an increased demand. This, in turn, forces a more intensive production, introduces a crossing of the ecological borders and therefore destroys the ecological basis of the satisfaction of basic needs - this exacerbates the situation (p. 21). In the search for appropriate solutions to the waste and waste water problems the authors keep in mind that the problems are, in part, more intensive than in the industrialized countries and affect the population more heavily. People are more dependent on their surroundings, because of the lack of an infrastructure which would compensate differing yields, and the insufficient hygienic conditions affect the highly sensible climate of the tropical and subtropical regions (p. 8/9). The creation of an ecologically appropriate assistance to the developing countries therefore precludes a solution based solely on transfers of technolo- 
gies and experiences from industrialized countries (p. 10/11); a special adjustment has to be made.

Within this context and with regard to wastes and waste waters Weimert et al. point out the different situation of the rural/agricultural and urban/industrial problems as well as the interweavings between them. The rural/agricultural problems in particular are caused by growing population which leads to an ecologically unacceptable form of intensification of agro-production. Here the authors concentrate, mainly, on the field of recycling wastes to use them as energy or manure, to reduce biocides and chemical fertilizers to conserve the natural resources, and to prevent a contamination of the ground waters (pp. 30-40). Besides these problems, which are to be solved mainly by the ways of production, they present a number of modes to treat wastes and waste waters in rural situations (pp. 202-243).

The authors pay attention to the problems of urban/industrial regions in their relation with the rural/agricultural situation. The situation in the rural regions contributes to the ongoing trends of migration to the industrial regions. Here urbanization takes the form of an excessive growth of slums without any form of infrastructure. The water of the rivers used in agricultural production is already polluted because of the lack of infrastructure in the urban centres. The authors point out that the already existing heavy development in the centralized industrial areas leads to pollutions that are typical of industrialized countries but do not exist to the same extent because of the existing laws and regulations and the infrastructures. With regard to this situation Weimert et al. present a number of modes and technologies for recycling and handling urban and industrial wastes and waste waters; these not only call for costs and investments but lead to the conservation of raw materials, energy and fertilizers - and within this context to the increase of employment (pp. 93-201).

Although the authors represent a firm of consulting engineers they are well informed about the social, political and economical problems of introducing the protection and conservation of the natural resources in developing countries. Their presentation of suitable technologies in rural/agricultural and urban/industrial situations follow a strategy to overcome the problems of introduction. Therefore the work of Weimert et al. is more than a contribution on the subject of technologies to use in waste and waste water problems in the Third World; it is also important information about the protection and conservation of natural resources in the developing process in the Third World. The fact that there is a bibliography of about 170 titles to give further information to an interested reader additionally upgrades the quality of this book.

\section{The Tanzanian Case: Regional Development by Eco-Farming}

On the case of ecodevelopment in Tanzania Bernhard Glaeser (1981) tries to demonstrate that this concept functions. In his view ecodevelopment has to unfold the "effects of trickling up" and he presents a concept of development oriented on the needs to 
harmonize economy and ecology (p. 7). Therefore, the population mentioned is integrated into the planning processes and is based on the satisfaction of basic needs, on self-reliance and on the environmental appropriateness (p. 8/9). For this strategy of development, not to a great extent concerned with the conditions of the political systems, is based upon the use of agricultural methods which are environmentally acceptable and energy saving (ecological), on a sufficient per capita income (economical), on an upgrading of the employment rate (national economy), on the compatability with specific local needs (social), on the compatability with traditions and values (cultural), and on the integration of the population into the planning of projects (political) (p. 9). On the questions of opportunities to increase incomes the aim of this study is to ascertain the social and economical conditions for the use of ecologically oriented agricultural production and the test of its range of use in the society of a developing country (p. 2/3). In this context he characterizes ecological farming (pp. 16-17) as a steered multiple system of mixed farming that integrates the use of trees and grounds; the production of animal food and the use of special cultures. He sees it as a circulation of energy and material characterized by the enormous use of biomass, by little mechanical soil tilling and by a system of biological control of erosion, by weed acceptance instead of chemical dam up, by the remunciation of maximum output instead of the stability of the agricultural ecosystem, and by the stabilization of the supply situation of the country. This form of development Glaeser does not see as an alternative to scientific and technological development, but as an other development in itself (p. 20). Ecological farming within this framework and these aims should be a means (p. 19) for a long lasting socio-economic development, for the production and accumulation of surplus in rural areas, for the food supply of the population in towns; it should also be a condition for the development of centres of craft and of small industries and for the development of a mixed economy and a division of labour.

The author tests this concept on a region in Tanzania, where there are few chances to realize family planning (p. 60). On the other hand, while the agricultural production has to increase to feed the growing population, and the endangering of the environment directly harms the basis of peasantry existence and on ongoing soil scarcity would reduce the social contacts among friends and family members of different villages as the farm work becomes more time consuming (p. 75).

If ecodevelopment within the framework of the Tanzanian region works it has to lead to increasing incomes, the protection of the socio-cultural structure, the employment and the feeding of the growing population, the economic development, the development of industrial centres in rural areas interlinked with the agricultural development, and - to realize this - a protection of environment and natural resources. With regard to this region at least the author is able do demonstrate that there is a real alternative to an agro-industrial intensification of agricultural use of the land. A special mixture of the plants and modes of use moreover will not only be environmentally appropriate but in the mean time will make the food situation more secure, will increase incomes and will unfold the need for appropriate technology, easy to produce in the urban centres of the 
rural region. But more important is the fact that the economic development in this region is most intensively influenced by the activities of the small holders; the income per day a man works increases as much or even more than it does by the modern ways of high-technology farming and in this way also the needs for appropriate technology are unfolded, which does not occur in the case of high-technology farming.

Evaluating these results, Glaeser asks whether they are representative. Here he points to the situation in the east-african highlands (p. 172). In the case of economic development he points out that ecodevelopment leads to a policy of decentralization and self-determination in production, that it leads to a reduction of dependency on the world market and an increase of employment and investment, and that it leads to the conservation of the natural resources, most important: the conservation of farm land (p. 188/189). Because of this situation national capital and foreign currency can be used for industrialization and for the set-up of infrastructures, which creates opportunities for internal reforms and legislation, but the author also calls attention to the difficulties of implementation (p. 189). But it is the self-reliance that makes the concept attractive to developing countries, there is no need for external capital aid and so there are no problems of repayment (p. 190/191).

So, to sum up, the author presents a concept of regional and decentralised economic development in a rural situation that is threatened by the growth of population and the destruction of the environment - and that is able to overcome these problems. The study is an interesting contribution to the discussion of the development in the Third World and - what seems to me more important - to the discussion of the environmental problems and the ways of land use. The example of Tanzania also shows how to manage the migration from the rural regions to the towns; but one has to keep in mind, that the author did not analyse the problems of feeding a growing population in the urban centres - there could be an influence on the need for increasing agricultural output - and the environmental connections between rural and urban regions. His aim was to demonstrate that ecodevelopment works in a regional and rural situation and is able to bring about not only environmental conservation, but economic development too; and this is shown by the Tanzanian example.

\section{The Chinese Case: Environment and the Satisfaction of Needs of a Growing Popu- lation}

The environmental problems which the developing countries face are represented in the situation of the People's Republic of China. With it's arctic north and it's tropical south, with it's internal deserts and it's coastal regions, with it's agricultural regions, faced with the need for increased productivity and with it's industrial regions, characterized by an enormous and rapid growth, with problems of rural poverty and with a migration-induced urban situation, China represents a mirco-cosm of the affected ecological system in the Thrid World. Although the information on Chinese problems is insufficient a lot 
of examples concerning ecological development in China have been reported - and some of them have been indeologically influenced. Even though they have some sympathy for the Chinese way of development Dieter Albrecht et al. (1980) try to analyse critically the ways of agricultural land use in China. Their aim is to find out, whether the use of nature is in fact ecologically conserving, and to discover how the social, economical and political factors influence the use of land, and which processes of development have been introduced to surmount the existing under-development (p. 17). Therefore, Dieter Albrecht analyses the relationship between the forms of possession and the ways of land use, Thomas Schneider discusses the 8-Point-Programme as a form of agriculture appropriate to nature, Ulrich von Dewitz and Manfred K. Goedecke present China's reforestation policies from the historical and socio-economical point of view, and Norbert Müggenburg introduces us into China's fight against desertification.

On the whole it is the contribution of Dieter Albrecht that characterizes this book. He concentrates on the conflicts that arise in planning and realization of an ecological land use under the condition of collective possession in rural regions (p. 21). But his conclusion that collectivization in agriculture was the motor of its development and that the increasing endangerment of ecology by economic development (pp. 84-85) does not show the afore-mentioned conflicts which arise from the form of possession. Nevertheless, Albrecht presents very precisely the relationship between society and ecology which are systematically connected by the form of agricultural production. By doing this he shows up the need for a reform of the distribution of land (to eliminate the lease-hold land system that induces the exhaustion of the soil), and he argues for the need to collectivize (to rationalize, to mechanize, to increase the yields and to upgrade the efficiency of organization in land use) and he stresses the need for economic planning in his developing country (chapter 2 and 3, pp. 27-58). But he does not discuss the problematic results of the enormous monocultural use of farm land (following the example of the American crop zones) and of the tendency to use land primarely to increase yields (p. 73). So it is interesting to read Albrecht's presentation of a counter-position to Glaeser (1981). In the case of reforestation, one of the most important objectives and one which is most necessary to protect the coastal regions against arctic and sandy storms, he points to the capital needed, capital which cannot be raised by the individual small-land holder, so here, in fact, collective activities are necessary (pp. 44-45). This discussion of the treatment of the 'hidden unemployed in the formation of bigger production units is interesting (pp. 51-52), as well as his explanation of the way in which the increase of yields by mechanization of the land use brings about the industrial production of farming machines (p. 56). Most problematical is his argument for a far-reaching planning as a means for the protection of environment and as an ecological way of agricultural production (pp. 65-66), while Glaeser (1981) was able to demonstrate that a system of small-land holders can also bring about the same results.

And above all Albrecht's interesting contribution is deeply affected by the information problem. Not only must the data he cites be handled with care (as there are no really valid data on China), but also when he speaks of the feeding of $25 \%$ of the population of 
the world with only $8 \%$ of the agricultural usable surface (p. 23) he does not give attention to the fact that about 100 million people are starving. He pays little attention to the Chinese development philosophy which was dominant until the end of the 70s, a philosophy which gives industrialization superiority - as is usual in the Third World - to the conservation of natural resources (p. 67). Instead, he is more interested in the discussion of the theoretical problem that is created by China's adoption of profit as an aim of economic activity (p. 84). And what the reader misses in Albrecht's treatment of land use under the influence of a new social system and in his discussion of the connection between agriculture and industry is ataking into account first of all, how industrial pollution affects agricultural production, secondly, of the connections between urban and rural regions in the use of waste and waste waters, and thirdly the existence of a highly developed recycling system.

Thomas Schneider also concentrates his contribution on agricultural production. Treating the 8-Point-Programme on agricultural development from 1956 to 1967 (first phase) and from 1968 to 1980 (second phase) and evaluating it as conducive to an agriculture appropriate to nature, he gives some information on the basic problems of agricultural production and its endangerment to nature. The programme aims at the methods of land use, fertilization, the use of water, the development and distribution of upgraded seed, the more productive ways of planting, the protection of plants, the improvement of planning and organization of production, and mechanization (p. 109). The positive results Schneider speaks of (p. 106) are reported by the New China News Agency; therefore, they have to be treated carefully and with a critical eye, especially as the problems existing in 1958 (p. 105), that is before the programme mentioned, tendentially still existed in 1980 when a West German commission visited China (see B. Glaeser (ed.), 1982). Thomas Schneider should therefore be read in the context of the continuing discussion of environmental problems in China.

These data problems also exist in the contribution of Ulrich von Dewitz and Manfred K. Goedecke on the reforestation policies in China. While they report that China's forest surface increased from 5 to $7 \%$ (1949) to 12,4\% (1978) (p. 178), the West German commission reports that there was no increase of the wood covered surface and that even the regions where there were vast forests several years ago, are seriously affected (Glaeser (ed.) 1982). So, it is better to read this part of the book as a report of attempts to bring about a reforestation in China and of Chinese problems in establishing forests, faced, with the lack of fire wood (p. 170) and with the conflict between farm-land and the surface required for the woods. Within this context it is interesting to know about the importance of collectivation and the role of hidden unemployed in rural areas (p. 156), about the reforestation farms (p. 166) and the need for vast forest regions as ecological protection (p. 179). The contribution of Norbert Müggenburg on activities against desertification also highlights these problems and should be read within this context. Above all, although there are some points to critisize (especially on the data used), the book gives an interesting introduction to the environmental and agricultural problems in China and to the problematic situation of a developing country with an affected ecology. 
But it should be read critically and not without the additional information in the books edited by Glaeser $(1982,1983)$.

Some years later another delegation, now sponsored by the German Ministry for Technology and Research, traveled through China. Their impressions and experiences on ecology and environmental protection are edited by Bernhard Glaeser (1982). The members of the delegation report, that because of their different fields of scientific research the inhomogeneous structure did not leave enough time for specific discussions. It is just this variation, however, that upgrades the book for these interested in the different fields of environmental policy. As regards ecological problems in the Third World, the example of China is interesting, as it did not overcome its environmental problems, but is able nonetheless to develop and to produce plants on the level of German quality (p. 1). In his introduction and survey Glaeser points out the main environmental problems of China, and thisway he highlights why it is interesting as an example of all Third World problems (pp. 23-53). The treating of urban wastes and a system of waste economy between the urban and the surrounding rural regions, the recycling of industrial raw material, the control of urban pollution, the conflict between industrialization and ecology - given the priority of industrialization as is usual in the Third World -, the ecological problems of agriculture, especially if there is an interaction with the urban industrial centres, and finally and most importantly the questions of law and administration.

Within this framework, the contributions of the members of the delegation provide interesting information on the situation in China, which makes it possible to take this country as an example to a great extent of the Third World. It is Johannes Küchler (pp. 55-112), who points out the connection between soil erosion and deforestation and the influence of migration processes in the endangerment of the natural resources. Here it is important that even those regions like Yunnan (p. 69) traditionally covered with forests, are seriously affected by wood felling which is 15 times higher than is ecologically acceptable, because the price of wood was freed of state regulations and, as a result, highly attractive. Thus, in Sichuan (p. 70) the surface covered with wood, was reduced from $19 \%$ in 1950 to $10 \%$ in 1982, the wood felling was 25 times higher than is ecologically acceptable. Küchler shows a direct relation between flooding and these deforestation activities. And last but not least he points out the close relation between migration, urbanization and the town-induced reduction of agricultural surface (pp. 75-77). Here it should be noticed, that Küchler pays attention to the obstactles to solving these problems, as long as studying agricultural and forestrial sciences is socially not attractive (pp. 81-86).

Complementary to the problems of the protection of natural resources, Bernhard Glaeser (pp. 113-158) presents his impressions of agricultural methods that conserve the natural environment. His contribution gives additional information on organic fertilization and biological protection of agricultural plants and on the importance which the use of biogas in rural and urban conditions has and could have in protecting the - still existing - forests and in utilising urban waste waters. Within this context he provides an interesting report on the daily collection of the wastes of the househoulds of the town, 
which are transported to the agricultural production units, and form in this way a systematic urban rural unit. Hans-W. Schlipköter (pp. 159-222) continues with the hygienic and health hazards of pollution. Here he shows the specific problems which could arise from this systematic urban/agricultural waste circulation to fertilize the fields. The insufficient treating of feces is one of the primary causes of schistosomiasis and the problems of mawworms in rural regions. In industrial regions, the pollution regulations, which allow much more destruction of environment than in industrialized countries - even if the environment has already been more affected -, lead to the typical health risks.

These problems of health are one side of the Chinese waste economy. The recycling of raw materials is the other, to which Werner Schenkel (pp. 273-301) pays attention. It is the problematic situation of the stock of raw materials that create the need for these activities (p. 278), and it is the fact that the value of recycled raw materials is 20 times as high as the wages of the workers engaged in this field, that makes recycling economically rational (p. 281). So within this context Schenkel reports on the system recycling urban wastes and their use in industry and as fertilizers in agriculture (pp. 282-288). In the case of the waste problems in rural regions he especially points out the use of biogas plants, which use the waste to produce energy, and fertilizers and to reduce hygienic risks (pp. 288-292) - as long as they work that is, as 30 to $40 \%$ of the 7 million plants usually do not (p. 288). Last but not least, his report is interesting, as he points out the environmental dangers are also the results of old fashioned production plants, and that only a little share of industrial wastes, is treated. So the planning of industrialization and urban development is reprorted as one of the main - structural - means to reduce environmental threat, and there is intensive interest in the West German know-how and technology. This interest in German technologies and know-how is also noticed by Bernhard Prinz (pp. 223-272) in the context of protection from immissions and the effects of immissions in the atmosphere. Prinz also remarked that the reasons for these activities tend not to originate from a desire to protect the environment, but from a preoccupation with the saving of raw materials (p. 277). So Prinz points to a close relation between the need for recycling and the effect of environmental conservation; a systematic context which is one of the basic points of the law for the protection of environment (pp. 230-231). To reduce the immissions and the effects on agricultural production, an attempt is made to arrive at a more diversified use of energy sources - e. g. the use of coal with a smaller percentage of sulphur and the use of hydro-energy - and a reform of the organization of industrial production. But to bring about more effective action presupposes sophisticated techniques of the measurement of immissions and the existence of an infrastructure of measuring - which is in the process of being constructured but does not as yet exist.

The final two reports of the members of the delegation, are somewhat lacking because much of the information included was already given before in other contributions. Otto Krause (pp. 303-332) reports on low-emission technologies that are to be developed and used in future, and he points out, as others have before him, that old fashioned plants, a 
lack of sewerage and rapid economic development are the problems of environmental production. S. H. Eberle (pp. 333-341) shows up the need for drinking water and the danger of waste waters.

The impressions and experiences of the West German delegation have been one of the basic sources of information for the reader Bernhard Glaeser (1983) edited on environmental policy in China. Here special attention is given to the context of modernization and environment, agriculture and generation of energy. In his introductory contribution Bernhard Glaeser points out the problems of environmental policy in China (pp. 9-44). As the delegation has offered an extensive information pool, there is little new to report; but what is more interesting here is the systematic context Glaeser unfolds. The economic relations within this part of the world, even though it is a socialist state represent as a microcosm the general problems. There are provinces that function as producers of raw materials, so that the structure of centre and periphery does exist as in the world economy (p. 14). The existing ecological problems within this unbalanced economic development are tackled in China by a new orientation of the policy. Here the author calls attention to the new general direction of urban and industrial planning, to the increasing recycling system and to the new environmental laws which are backed up by an administration better equipped to control pollution (pp. 18-20). This can indeed change the way of economic development and industrialization as is pointed out (p. 26), and it could make the Chinese way of development one which is aware of the importance of the conservation of the natural resources.

But the fact that these aims are not reached solely with new laws and new administrative guidelines is made clear by the first contribution of Cheung-Lieh Yu (pp. 47-78). Within the part that is concerned with developmental policies during the last four decades he shows that the enthusiasm for economic growth still exists and that environment plays a less important role therein (p. 56) - in China the economic development is expected to generate the financial and technological conditions to repair the environmental damages (ibid.). But Cheung-Lieh also leads our attention to a turning point in this situation, which he identifies in 1980 (p. 63). In his second contribution (pp. 113-142) he treats of the reform of the administrative system and an new form of the organization of production. It is particularly the cooperation among institutions because of economically motivated environmental protection (pp. 125-133) and the organized agro-industrial combination (pp. 134-140) that is worthy of attention. Here the author shows the chances for modernization in industry accompanied by a systematic organizational protection of environment. This treatment of the argument is also presented by Axel Troster (pp. 79-112), who points out the slow changing within the already existing industrial system and the new ways of planning in recently erected plants.

The second part of this reader deals with modernization and environment in agricultural production. Here Bernhard Glaeser again gives a contribution (pp. 145-175) on the importance of environment in Chinese policy, with regard in this case to the agriculture. What is interesting is his argument that there is a close relation between environmental protection and economic stimuli when accompanied by partial reprivatisation. The 
modernization brought about increased mechanization, irigation, fertilization, use of upgraded seed and also by reorganized management is realized (p. 161) in the big farming communities; and the small-land holders who are now involved in about $25 \%$ of the Chinese agriculture (p. 171) play an important role in assuring the ecological balance. The modernization of agriculture, accompanied by environmental protection, is therefore closely related to reform of the societal organization.

Modernization in agriculture is something that is also concerned with the use of mineral fertilizers and pesticides. Here Rudolf G. Wagner (pp. 177-250) pays attention to the problem of how to assure high yields in the long-range. Particularly he is concerned with fertilizers with a base of human acid and with the integrated system of biologically-based pest control. In a very detailed analysis he points out, that these fertilizers, used to modernize Chinese agriculture, fit into the conditions of the country and are part of self-reliant solution and of an environmental protection which is basic to agriculture and to its increasing yields (p. 205). In the case of an integrated pest control Wagner shows the problem that exists in realization because of the lack of qualified personnel and the exclusive use of this form of pest control in the field of agricultural communes, which make up about $30 \%$ of this surface (pp. 247-248). But to ensure agricultural production an ecologically appropriate sharing of the land surface with forests is necessary. Here Dirk Betke (pp. 251-299) gives a contribution, which is mainly based on the information of the delegation's report on the basis of which he evaluates the Chinese reforestation policies within the context of the growth of population, of energy demand and supply, and in the context of the political system.

The third part of this book is concerned with the problems of modernization and environment in the energy sector. Here Wolfgang Kinzelbach (pp. 305-324) pays attention to the pollution problems, Thomas Clauser (pp. 325-364) points out the importance of small hydro-power to the Chinese development, and it's environmental appropriateness, and Rudolf G. Wagner (pp. 365-394) in his second contribution deals with the already famous use of biogas in China. This part especially is interessting because of the connection between economical development and the need for energy (about 20-30\% of industrial capacity cannot be used because of the lack of electricity) on the one hand, with the contaminated environment and its effects on agricultural production (that also has an increasing need of energy) on the other hand.

The final part of this book is composed of the second contribution of Wolfgang Kinzelbach (pp. 397-415) who gives a more general overview on environmental protection in China, and a contribution by Heiner Dürr (pp. 417-463) who pays attention to the political problems of ethnic minorities in this context. Although these contributions are interesting, they are affected by the ongoing problem of the lack of information and by the fact that China is just at a turning point without already having turned. So altogether the reader Bernhard Glaeser edited is highly interesting and provides information additional to the delegation's report, not only in the field of empirical problems but also in the context of a more systematic view. Even though there is not a great deal of attention paid to an all-embracing theory of ecology and economy, the information 
which is included on the economic social and political aspects, in addition to the specific question of the conservation of environment, upgrades the reader. So the two books edited by Glaeser $(1982,1983)$ are particularly basic to Chinese problems and to the question of ecology and economy in the Third World in general.

\section{The Kenyian Case: Financing the Protection of Environment by a Increasing Indus- trialization}

Kenya is an example of a capitalist way of development. So, besides the fact that Peter Bartelmus (1980) is living there as a member of the staff of UNEP; it is not by chance that he works out a statistical method to value the relation between economy and ecology on the basis of the costs. After having introduced the economic-environmental system (chapter 1, pp. 7-39), he discusses the comparative measurement of economic welfare and environmental welfare losses (chapter 2, pp. 40-69). Here he points out, that the pollution of the environment and the endangerment of natural resources is not only a question of the ecological system but also a problem of economic welfare. If on the one hand pollution is a result of economic growth and development, on the other hand it causes need for costly repairs and affects the existing economic system, especially the agricultural production. These relationships he demonstrates in the case of Kenya (chapters 3 and 4, pp. 70-117), where he shows up the impact of industrialization on the natural environment (pp. 72-80) and presents the effects very precisely listed in a table (pp. 74-75). As well as this, he gives informations on the environmental impact of consumption (pp. 80-81) and of human environment (pp. 82-83), also listed precisely in tables (p. 81 and 83). Finally he argues, that there are environmental welfare losses because of the economic development (pp. 103-114), also listed with data in tables.

So far Bartelmus is able to demonstrate what he wanted to show: that the environmental losses must not only be evaluated in ecological terms, but have an economic effect too. Thisway, his contribution is an important part of the discussion of environmental protection in the Third World and can lead to more attention being paid to ecological effects of industrialization in developing countries. But the statistical system of Bartelmus does more, and here it begins to be questionable: it is a comparison between the economic effects of industrialization and the costs of a damaged ecology. That means, as long as the effects are higher than the costs, then it would be rational not to change the polluting system of industrialization but to repair it afterwards. So a development that induces cultural and social changes that are not appropriate to the society and damages the natural resources that affect the ecological system is acceptable, as long as the costs of reparation (which cannot mean a reconstruction of the originally existing system) are less than the economic effects. Therefore, the contribution of Bartelmus has its limitations. Even if it is a suitable and helpful method of valuing development projects it easily leads to an over-emphasizing of the economic side. 


\section{Summary}

The reviewed books certainly give a lot of information and are mostly very detailed on the interconnecting problems of economy and ecology because of the socio-economic development in the Third World. They show that there is a close relationship between the conditions of the conservation of natural resources and their economic costs, which provides chances to realize those concepts that save money. They also point out that modes of agricultural production and rural conservation of natural resources - such as eco-farming and reforestation - are important, but that there is intensive need for the control and reduction of urban and industrial pollution. So far, the authors have given less attention to the systematic relationship within the countries of the Third World - the opportunities and obstacles of an ecologically acceptable interlinked urban and rural system -, and because the industrialized countries possess the most capable research structures to develop the technologies needed. The authors gave very little attention to the importance of the system of the international division of labour - which is directly involved in this context - and the input therein. They made important contributions to the discussion, however in terms of information and of partial systmatic analyses.

Ulrich Hilpert

\section{Literature}

Albrecht, Dieter/Dewitz, Ulrich von/Goedecke, Manfred K./Müggenburg, Norbert/Schneider, Thomas (1980): Landnutzungsplanung in China. Ein ökologischer Entwicklungsweg? Berlin: Oberbaum, $216 \mathrm{p}$.

Bartelmus, Peter (1980): Economic Development and the Human Environment. A Study of Impacts and Repercussions with particular Reference to Kenya. München \& London: Weltforum Verlag, 184 p.

Glaeser, Bernhard (1981): Okoentwicklung in Tanzania. Ein empirischer Beitrag zu Bedürfnissen, Selbstversorgung und umweltschonender Agrartechnologie im kleinbäuerlichen Betrieb. Saarbrücken \& Fort Lauderdale: Breitenbach, 209 p.

Glaeser, Bernhard (ed.) (1982): Ökologie und Umweltschutz in der VR China. Eindrücke und Erfahrungsberichte einer Umweltdelegation. Bochum: Brockmeyer, 341 p.

Glaeser, Bernhard (ed.) (1983): Umweltpolitik in China. Modernisierung und Umwelt in Industrie, Landwirtschaft und Energieerzeugung. Bochum: Brockmeyer, 463 p.

Hartje, Volkmar J. (1982): Umwelt- und Ressourcenschutz in der Entwicklungshilfe: Beihilfe zum überleben?. Frankfurt/M. \& New York: Campus, 142 p.

Riddell, Robert (1981): Ecodevelopment. Economics, Ecology and Development. An Alternative to Growth Imperative Models. Westmead: Gower, xxii p. + 218 p.

Weimert, Winrich F./Kress, Reinhold/Karpe, Hans-Jürgen (1981): Umweltprobleme und nationale Umweltpolitiken in Entwicklungsländern. Ansatzpunkte zur Förderung im Rahmen der wirtschaftlichen Zusammenarbeit. Dargestellt am Beispiel der Wiederverwendung von Abwässern und Abfällen. München \& Köln \& London: Weltforum Verlag, 276 p. 